\title{
CORRIGENDUM
}

\section{The purpose shapes the vocative: Prosodic realisation of Colombian Spanish vocatives - CORRIGENDUM}

\author{
Clara Huttenlauch, Ingo Feldhausen \& Bettina Braun
}

doi:10.1017/S0025100317000597, published online by Cambridge University Press, 16 April 2018.

In the JIPA article 'The purpose shapes the vocative: Prosodic realisation of Colombian Spanish vocatives', in the list of references, on page 56, the citation of GREGORY Ward and Julia Hirschberg's (1985) article has been mistakenly attributed to NigEL Ward and Julia Hirschberg. The correct entry is: 'Ward, Gregory \& Julia Hirschberg. 1985. Implicating uncertainty: The pragmatics of the fall-rise intonation. Language 61, 747-776.'

\section{Reference}

Huttenlauch, Clara, Ingo Feldhausen \& Bettina Braun. 2018. The purpose shapes the vocative: Prosodic realisation of Colombian Spanish vocatives. Journal of the International Phonetic Association 48(1), 33-56. doi:10.1017/S0025100317000597. 